\title{
Self-palpation Feedback for Abdominal Hollowing Exercise
}

\author{
Young-kyun Kim', Min-ra Choi', Seong-jun Kim¹', Ki-kwang Lee' ${ }^{1}$ Hye-ree Kim*
}

${ }^{7}$ Kookmin University, Seoul, Korea

Received: March 7, 2018

Accepted: April 23, 2018

Published online: April 30, 2018

Keywords:

Abdominal hollowing exercise

Abdominis muscle

Low back pain

Pressure biofeedback

Self-palpation
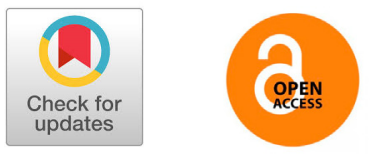

\begin{abstract}
PURPOSE The purpose of this study was to investigate abdominal muscles' thickness change during abdominal hollowing with self-palpation feedback.

METHODS Twenty six healthy males participated in this study. Subjects were instructed how to perform AHE on hook-lying position. Ultrasound images (transverse abdominis (TA), internal oblique (IO), external oblique (EO)) were measured during resting and AHE using self-palpation feedback or pressure biofeedback.

RESULTS TA thickness increased significantly with both self-palpation feedback and pressure biofeedback groups ( $p<.05)$. In TA, the control group showed more increased thickness than the experimental group. However, there was no interaction between AHE and using pressure biofeedback in $\mathrm{IO}$ and EO. Also, all subjects's muscle thickness of $\mathrm{IO}$ were increased $(p<.01)$ and EO were decreased $(p<.05)$ significantly.

CONCLUSIONS Self-palpation feedback during AHE is useful to perform AHE. Therefore self palpation feedback is a simple method to provide feedback when ultrasound and biofeedback equipment are no available.
\end{abstract}

(c) The Asian Society of Kinesiology and the Korean Academy of Kinesiology
서론

요통(Low back pain; LBP)은 현대 사회에서 가장 만연 한 질병 중의 하나이다. 인구의 약 $60-80 \%$ 가 일생 동안 한 번 이상 요통을 경험하며, 그중 $80-90 \%$ 는 보통 3 달 안에 증 상이 완화되지만, 재발되는 것이 일반적이다(Hides et al., 1996; Long et al., 1996). 이 때문에 요통을 위한 다양한 치료 방법들이 개발되어져 왔다. 일반적으로 요통 환자들은 와 식, 좌식생활 등을 피하고 정상적인 생활 패턴으로 돌아가 는 것이 좋다고 알려져 있으며, 또한 전신 운동을 실행하 는 것이 효과적이라고 보고되었다(Maher et al., 1999). 그러 나최근 연구에서는 일반적인 전신 운동 프로그램과 더불 어 직접적으로 요추 근육을 운동하는 것을 강조하고 있다. 이러한 운동은 보다 더 효과적이고 효율적인 치료를 위해

*Correspondence: Hye-ree Kim, Kookmin University, 77 Jeongneung-ro, Seongbuk-gu, Seoul, 02707, Republic of Korea.

E-mail:05121112@hanmail.net
척추 및 골반(lumbar-pelvic)과 관련된 근육들의 안정성에 초점을 맞추어 발전되었다(Richardson et al., 1999).

몸통 안정화 운동(core stability exercise)은 복부(abdominal)와 요추(lumbar spine) 심부 근육의 동원 패턴과 타이 밍을 향상시키는 것으로 알려져 있다(O' sullivan et al., 1997). 따라서 이러한 운동은 만성 요통이나 요통이 재발 한 사람들을 위해 주로 처방된다(O' sullivan et al., 1998). 요통 환자들이 처방받는 몸통 안정화 운동의 초기 단계에 서는 복부 당기기 운동(abdominal hollowing exercise; AHE) 으로 알려진 drawing-in방법을 사용한다. Drawing-in 방법 은 복부 심부 근육의 안정화에 가장 좋은 효과를 가지며, 요통의 원인이나 그 결과에 상관없이 치료와 재발 방지에 효과적이라고 보고되었다(Kisner \& Colby, 2012).

정확한 $\mathrm{AHE}$ 를 하기 위해서, 환자들은 외복사근(external oblique; EO), 복직근(rectus abdominis; RA), 또는 척주 기립근(erector spinae)의 수축을 하지 않고 전외측(anterolateral) 심부 복근, 특히 복횡근(transverse abdominis; TA)과 내복사근(internal oblique; IO)을 수축하는 것을 배워야 한 
다(O’ Sullivan et al., 1997). 그러나 현장에서 TA 수축의 지 도를 위해 초음파를 이용하는 것이 비용적, 시간적 제한 이 크다. 이 때문에 AHE를 배우고 가르치기 위해서 일반 적으로 압력 바이오피드백 기구(pressure biofeedback unit) 를 이용하여 훈련하는 방법이 많이 사용되고 있다(Lee et al., 2013; Jung et al., 2014; Park \& Lee, 2013). 압력 바이오피 드백 기구는 근육이 수축할 때 그 힘을 기구에 전달하여 해당하는 압력을 표시해 주는 장비로서, 목표 근육의 운 동을 돕는 역할을 한다(Yun \& Kim, 2013). 압력 바이오피 드백 기구를 사용하여 근수축 훈련을 수행한 뒤, 목표 근 육의 실제 수축 여부를 확인하기 위해서는 실시간 초음파 영상(real-time ultrasound imaging)이 주로 사용된다(Hides et al., 1995). 초음파 검사는 비침습적(noninvasive)으로 복 부 심부 근육들의 크기와 활동 상태를 측정할 수 있는 도 구이며, 시각적인 피드백을 제공하여 자세조절 능력을 향 상시킬 수 있다(Kwon et al., 2011). 하지만 이런 방법은 요 통 환자에게 있어서 압력바이오피드백 기구와 초음파가 있어야 하는 어려움이 있다. 따라서 요통 환자들의 AHE 수행 여부를 확인할 수 있는 접근성이 용이한 피드백이 필요하다.

대상자가 편안하게 누운 상태에서 전외측 복벽(anterolateral abdominal wall)을 초음파 촬영을 하면 3개(TA, EO, $\mathrm{IO})$ 의 분리된 근육층을 확인할 수 있다. 대상자가 $\mathrm{EO}$ 및 $\mathrm{RA}$ 와 분리하여 $\mathrm{TA}$ 와 $\mathrm{IO}$ 를 수축하는 데 능숙하다면 $\mathrm{EO}$ 와 $\mathrm{RA}$ 가 두꺼워지는 것을 최소화하면서 IO 쪽으로 부착되 어 있는 TA만이 두꺼워지는 것을 확인할 수 있다(Hodges et al., 2003). Goldby, et al.(2006)은 초음파를 사용하여 TA 활성화에 대한 피드백을 주는 것이 언어적인 피드 백으로 운동을 가르치는 것보다 더 좋은 결과를 가져 왔다고 보고 하였다. 또한, Kwon, et al.(2011)은 복부 drawing-in 훈련 시 초음파 영상으로 시각적 피드 백을 받은 집단과 받지 못한 집단을 비교 하였는데, $\mathrm{TA}$ 의 두께 차이가 각각 $37 \%, 17 \%$ 증가하는 것을 확인하였다.

Lee, et al.(2013)은 압력 바이오피드백을 이용하여 Abdominal Drawing-In Maneuver(ADIM) 시 복부 근육이 가 장 활성화되는 다리 각도를 확인했고 Jung, et al.(2014)은 복부 근육의 활성화 차이를 standing과 supine 자세에서 비 교했다. 또한, $\mathrm{ADIM}$ 시 압력 바이오피드백을 사용할 때 는 그 값을 $40 \mathrm{mmHg}$ 를 기준으로 약 $0-2 \mathrm{mmHg}$ 증가가 복 부 근육 트레이닝에 효과적인 것을 확인했다(Park \& Lee, 2013). 그러나 대상자가 스스로 AHE를 수행할 때 TA를 수
축하는 것을 확인하기 위해서 매번 압력 바이오피드백 기 구와 초음파를 사용하기는 쉽지 않다. 하지만 운동하는 대상자가 자신의 심부복부근육의 수축에 대하여 정확한 피드백을 받을 수 있다면 AHE 운동에 대한 피드백을 전 달하기 간편해질 수 있다. AHE의 목적은 요부의 안정성 을 높이기 위한 요통 관련 재활운동으로 $\mathrm{TA}, \mathrm{IO}, \mathrm{EO}$ 의 수 축 패턴이 중요하다. 하지만 이에 관한 연구가 현재까지 이루어지지 않았다. 따라서 본 연구의 목적은 대상자가 $\mathrm{AHE}$ 를 수행하는 과정에서 압력 바이오피드백 기구의 사 용과 자가촉진에 따른 심부 복부 근육의 수축 차이를 비 교하는 것이다

\section{연구방법}

\section{연구대상}

본 연구에서는 건강한 20대 남성 26명을 대상으로 실 험하였다. 연구 대상자는 압력 바이오피드백 기구를 이 용하여 $\mathrm{AHE}$ 를 실시한 대조군 13명과 압력 바이오피드백 기구 없이 자가촉진 피드백으로 $\mathrm{AHE}$ 를 실시한 실험군 13 명으로 무작위 분류되었다. 대상자의 신체정보는 < Table $1>$ 과 같다. 실험을 수행하기 전에 대상자들에게 실험에 대해 이해할 수 있도록 설명을 충분히 하였으며, 이를 듣 고 실험에 동의한 사람들은 동의서에 서명하였다. 대상자 중 실험 이전에 복부 쪽에 외과적인 수술 경험이 있거나 일상생활에 영향을 줄 수 있는 요통 또는 고관절 통증(hip pain)이 있는 사람들은 실험 대상에서 제외되었다(Teyhen et al., 2005). 또한 신경학적인 문제를 가지고 있거나 실 험 자세를 견딜 수 없는 사람도 제외되었다(Richardson et al., 1992).

\section{측정장비}

본 연구에서는 $\mathrm{TA}, \mathrm{IO}, \mathrm{EO}$ 의 두께 변화를 살펴보기 위 해 초음파 장비 (logiq 200 Series, GE Healthcare, USA) 1대와 $3.5 \mathrm{MHz}$ 의 linear probe를 사용하였다(Figure 1). 또한, AHE 를 보조하기 위하여 압력 바이오피드백 기구 1개(Chatta-

\begin{tabular}{ccccc}
\multicolumn{6}{l}{ Table 1. Physical characteristic of subjects $(\mathrm{M} \pm \mathrm{SD})$} \\
\hline Group & $\mathbf{n}$ & age (yr) & height $(\mathrm{cm})$ & weight $(\mathrm{kg})$ \\
\hline Control & 13 & $24.5 \pm 1.3$ & $175.9 \pm 4.5$ & $77.1 \pm 7.0$ \\
\hline Experimental & 13 & $22.3 \pm 2.0$ & $175.2 \pm 6.2$ & $71.7 \pm 8.6$ \\
\hline
\end{tabular}




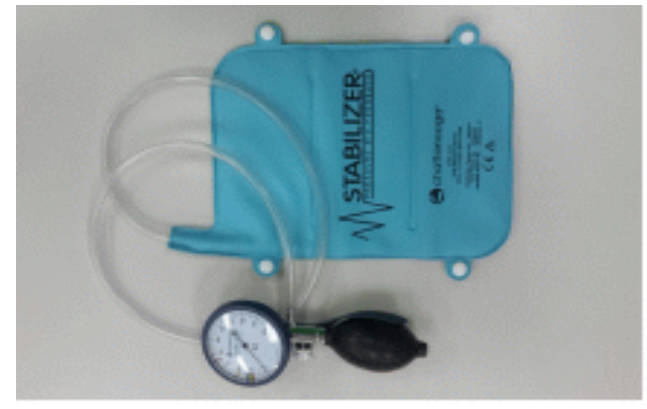

Figure 1. Pressure biofeedback

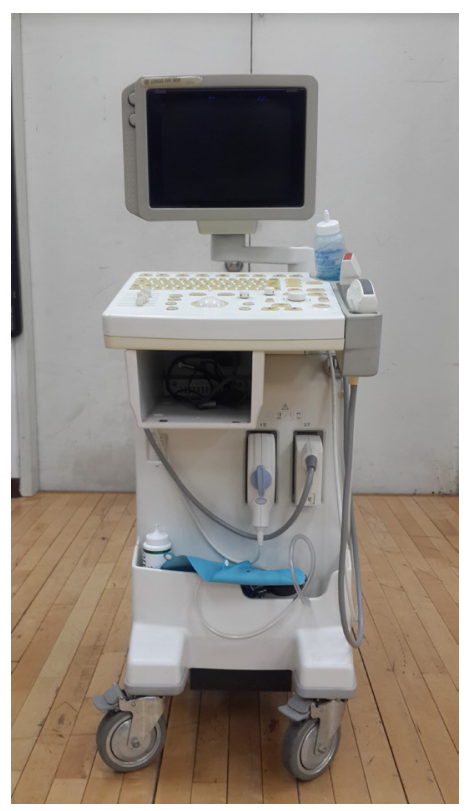

Figure 2. Ultrasound system

nooga Stabilizer Group Inc, Hixson, TN, USA)가 사용되었 다(Figure 2).

\section{실험설계 및 절차}

대상자들은 hook-lying 자세를 한 뒤 요추가 바닥 쪽으 로 납작해지고, 압력이 증가하는 것을 느끼면서 움직임 을 수행하도록 지도받았다. 또한, 머리와 상체는 안정적 으로 가만히 유지하였으며 발은 앞으로 당기거나 밀지 않 도록 하였다(Henry \& Westervelt, 2005). 대상자들은 이러 한 방식으로 계속 수축을 유지하면서 편안한 상태에서 호 흡을 계속하도록 지시받았으며, 운동 중 흉곽 아랫부분 (lower rib cage)이 내려갈 경우 실패한 것으로 간주하였다 (Richardson et al., 1992).

본 실험의 데이터 수집을 위하여 첫 번째로 대상자들
의 휴식상태에서의 초음파 영상을 수집하였다. 그다음, 대조군과 실험군은 각각 바이오피드백을 적용하는 $\mathrm{AHE}$ 방법과 자가촉진 피드백을 이용하는 $\mathrm{AHE}$ 방법에 대한 연 습을 3회씩 실시하였다. 이후, 대조군 대상자들은 압력 바 이오피드백 기구의 압력을 $20 \mathrm{mmHg}$ 로 맞춘 뒤 PSIS에 기 구의 아래쪽을 위치시켜 $\mathrm{AHE}$ 를 실시하였다. 압력 바이오 피드백 기구의 압력이 $40 \mathrm{mmHg}$ 가 되는 순간 초음파 영상 을 수집하였다. 실험군 대상자들은 압력 바이오피드백 기 구 없이 $\mathrm{AHE}$ 를 실시하였다. 대상자들 $\mathrm{TA}$ 의 수축을 스스 로 촉진하기 위하여 ASIS(Anterior Superior Iliac Spine)의 inferior-medial 방향으로 $2.5 \mathrm{~cm}$ 부위에 중지를 위치하여 $\mathrm{AHE}$ 시 근육 수축이 느껴질 때(Henry \& Westervelt, 2005) 검사자에게 반대 손가락만을 올려 신호를 주었으며, 연 구자는 초음파 영상을 촬영하여 각 근육의 두께를 측정하 였다(Figure 3). 이 과정은 2회 반복 수행되었으며 각 수행 의 평균값이 데이터 분석에 사용되었다. 표준화된 초음 파 영상을 얻기 위하여 검사자는 11 번째늑연골과 장골능 사이의 중간 지점에 linear probe를 위치하였다(Park, 2010; Teyhen et al., 2005). 각 근육의 두께측정은 영상의 정중앙 에서 수직선을 그어 흰색 영상으로 나타나는 근막의 윗 경계 끝에서 아랫경계 끝을 연결하여 길이를 측정하였다 (Ha et al., 2013)(Figure 4).

\section{자료처리}

휴식상태와 $\mathrm{AHE}$ 중 압력 바이오피드백 기구의 사용 유무에 따른 TA, IO, EO 근육 두께 차이를 알아보기 위하 여 이원반복분산분석(two-way repeated measure ANOVA) 을 실시하였으며, 대조군과 실험군 내의 차이는 paired t-test를 실시하였다. 모든 유의 수준은 $a=.05$ 로 설정하였 다.

\section{결과}

휴식상태와 AHE, 그리고 압력 바이오피드백 기구 사 용 유무에 따른 근육 두께 차이는 다음과 같다.

$\mathrm{TA}$ 에서는 $\mathrm{AHE}$ 운동 여부와 압력 바이오피드백 기구 사용 여부에 따른 상호작용이 통계적으로 유의하게 나 타났다 $(\mathrm{F}=7.015, \mathrm{p}<.05)$. 또한 대조군 $(\mathrm{p}<.001)$ 과 실험군 $(\mathrm{p}<01)$ 모두 휴식상태보다 $\mathrm{AHE}$ 시 $\mathrm{TA}$ 의 두께가 증가하는 것으로 나타났다(Table 2, Figure 5). IO와 EO에서는 $\mathrm{AHE}$ 운동 여부와 압력 바이오피드백 기구 사용 유무에 따른 


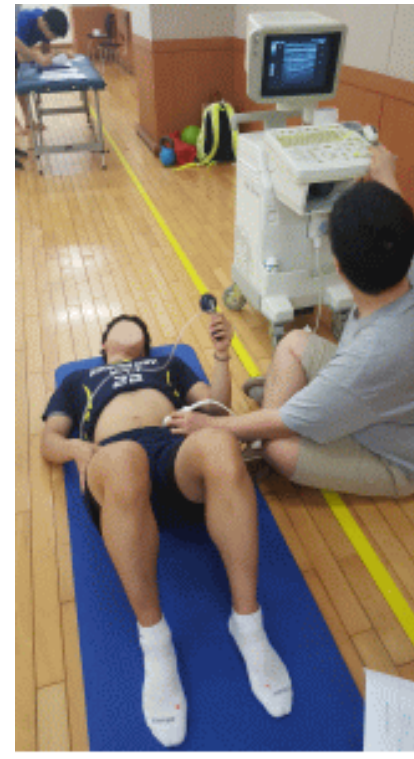

Figure 3. Data acquisition

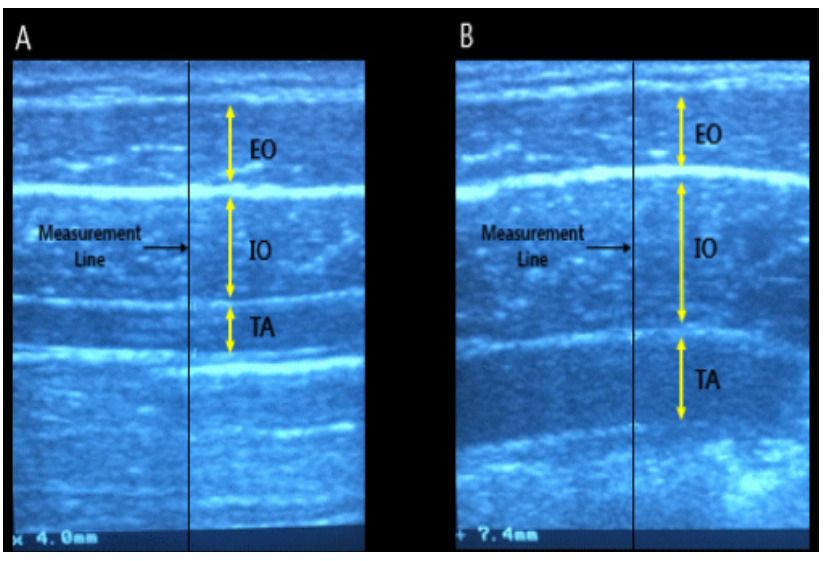

Figure 4. Ultrasound imaging of abdominal muscles A:rest, B:AHE

상호작용은 나타나지 않았다. 하지만 $\mathrm{IO}$ 에서 대조군과 실험군 내의 휴식상태와 AHE는 각각 유의한 차이를 보 였다 $(\mathrm{p}<.000, \mathrm{p}<.01$, Table 3, Table 4).

$<$ Table 5>는 휴식상태와 AHE 시 각 근육의 두께 차이 를 나타낸 결과로, $\mathrm{TA}$ 와 IO는 $\mathrm{AHE}$ 시 각각 $82.41 \pm 57.09 \%$, $26.55 \pm 25.08 \%$ 정도 근육 두께가 두꺼워져 통계적으 로 유의한 차이를 확인할 수 있었으며 $(\mathrm{p}<.001), \mathrm{EO}$ 는 $-7.76 \pm 16.87 \%$ 정도 근육 두께가 감소하여 통계적으로 유 의한 차이가 나타났다 $(\mathrm{p}<.05)$.

\section{논의}

본 현대 사회에서 가장 흔한 질환 중 하나인 요통은 변 화된 생활환경으로 인해 그 환자가 점점 증가하고 있다. 이를 위해 재활이나 물리치료 등 여러 분야에서 요추 안 정화 운동으로 $\mathrm{AHE}$ 를 사용하고 있다. $\mathrm{AHE}$ 는 요추 안정 화를 위해 가장 기본적으로 사용되는 방법으로써 팔다리 가 움직이기 이전에 몸통을 안정화시키기 위하여 $\mathrm{TA}$ 와 다열근(multifidus)의 동시수축(coactivation)을 활성화시 키기 위한 운동이다(O' sullivan et al., 1998; Teyhen et al., 2005). 이 운동은 활동적인 움직임을 수행할 때 몸통의 심부 근육을 먼저 활성화시키는 것에 초점을 두어 요추 (lumbar spine)의 안정성을 증가시켜주며, 요통과 관련된 증상들을 완화시켜주는 것으로 알려져 있다(O' sullivan et al., 1997; Richardson et al., 2002). 하지만 AHE는 다른 검 사자 또는 초음파 장비를 이용하여 피드 백을 받아야 하고 (Hides et al., 1995; Goldby et al., 2006; Kwon et al., 2011), 압력 바이오피드백 기구를 이용한 훈련을 하여야 한다는 단점 이 있다. 따라서 본 연구에서는 대상자가 AHE시에 압력 바이오피드백 기구가 없이 복부의 심부 근육을 활성화시 킬 수 있는지 알아보고자 하였다.

본 연구에서 자가촉진시 모든 대상자의 휴식상태와 $\mathrm{AHE}$ 사이의 $\mathrm{EO}, \mathrm{IO}, \mathrm{TA}$ 의 두께 변화를 살펴본 결과, 휴식 상태보다 $\mathrm{AHE}$ 시 $\mathrm{TA}$ 의 두께는 약 $82.41 \%$ 증가하였고, $\mathrm{IO}$ 는 약 $26.55 \%$ 증가하였으며 $\mathrm{EO}$ 의 두께는 약 $7.76 \%$ 감소하 는 것을 확인할 수 있었다. 초음파 이미지를 통하여 복부 근육 두께의 신뢰도를 연구한 Hides, et al.(2007)의 연구 또 한 본 연구의 결과와 마찬가지로 $\mathrm{IO}$ 와 $\mathrm{TA}$ 가 각각 $16.7 \%$, $41.2 \%$ 두꺼워지는 결과를 나타내었다. Critchley(2002)는 LAHE(low abdominal hollowing exercise)시 IO는 22.0\%, TA 는 약 $49.7 \%$ 증가한다고 하였고 $\mathrm{AHE}$ 시 $\mathrm{TA}$ 뿐 아니라 IO 또한 약간 수축된다고 보고하였다. 선행 연구들과 비교해 보았을 때 본 연구의 결과와 일치 하였으며, 자가촉진을 통한 $\mathrm{AHE}$ 훈련이 가능한 것으로 판단된다.

또한, 본 연구에서 $\mathrm{AHE}$ 운동 시 압력 바이오피드백 기 구의 사용 여부에 따른 차이를 분석한 결과, $\mathrm{EO}$ 에서 그 룹에 따른 상호작용이 $\mathrm{p}=.388$ 로 통계적으로 유의미한 차 이를 확인할 수 없었다. 따라서 $\mathrm{EO}$ 는 압력 바이오피드백 기구 사용 여부에 따른 효과가 발생하지 않았다고 판단 된다. IO 또한 압력 바이오피드백 기구 사용에 따른 차이 가 발생하지 않았다 $(\mathrm{p}=.096)$. 이원반복분산분석 결과 TA 
Table 2. Thickness of Transverse abdominis $(M \pm S D)$

\begin{tabular}{ccccccc}
\hline Group & $\mathrm{n}$ & Position $(\mathrm{mm})$ & Thickness $(\mathrm{mm})$ & & Difference $(\mathrm{mm})$ & Interaction \\
\hline \multirow{2}{*}{ Control } & \multirow{2}{*}{13} & Resting & $3.38 \pm 0.54$ & $\mathrm{t}=-8.772$ & \multirow{2}{*}{$2.96 \pm 0.68$} & $\mathrm{~F}=7.015$ \\
& & AHE & $6.36 \pm 1.22$ & $\mathrm{p}=.000^{* * *}$ & & $\mathrm{p}=.014^{*}$ \\
\multirow{2}{*}{ Experimental } & 13 & Resting & $3.11 \pm 0.98$ & $\mathrm{t}=-3.992$ & \multirow{2}{*}{$1.84 \pm 0.2$} & $\mathrm{p}=.002^{* *}$ \\
\hline
\end{tabular}

" $\mathrm{p}<.05$, AHE: Abdominal Hollowing Exercise

Table 3. Thickness of Internal Oblique $(M \pm S D)$

\begin{tabular}{|c|c|c|c|c|c|c|}
\hline Group & $n$ & Position(mm) & Thickness(mm) & & Difference $(\mathrm{mm})$ & Interaction \\
\hline \multirow{2}{*}{ Control } & \multirow{2}{*}{13} & Resting & $9.15 \pm 1.88$ & $t=-3.066$ & \multirow{2}{*}{$1.55 \pm 0.5$} & \multirow[b]{2}{*}{$\mathrm{F}=2.997$} \\
\hline & & AHE & $10.7 \pm 2.38$ & $\mathrm{p}=.010^{* *}$ & & \\
\hline \multirow{2}{*}{ Experimental } & \multirow{2}{*}{13} & Resting & $8.55 \pm 1.94$ & $t=5.278$ & \multirow{2}{*}{$2.84 \pm 0.81$} & \multirow[t]{2}{*}{$p=.096$} \\
\hline & & AHE & $11.39 \pm 2.75$ & $\mathrm{p}=.000^{* * *}$ & & \\
\hline
\end{tabular}

\begin{tabular}{|c|c|c|c|c|c|c|}
\hline Group & $\mathrm{n}$ & Position(mm) & Thickness(mm) & & Difference $(\mathrm{mm})$ & Interaction \\
\hline \multirow{2}{*}{ Control } & \multirow{2}{*}{13} & Resting & $7.34 \pm 1.04$ & $\mathrm{t}=1.552$ & \multirow{2}{*}{$-0.48 \pm 0.33$} & \\
\hline & & AHE & $6.86 \pm 1.37$ & $p=147$ & & $\mathrm{~F}=.774$ \\
\hline \multirow{2}{*}{ Experimental } & \multirow{2}{*}{13} & Resting & $6.06 \pm 1.28$ & $\mathrm{t}=1.596$ & \multirow{2}{*}{$-0.5 \pm 0.55$} & \multirow[t]{2}{*}{$\mathrm{p}=.388$} \\
\hline & & AHE & $5.56 \pm 1.83$ & $\mathrm{p}=.146$ & & \\
\hline
\end{tabular}

\begin{tabular}{|c|c|c|c|c|c|c|}
\hline Muscle & $\mathrm{n}$ & Resting(mm) & $\mathrm{AHE}(\mathrm{mm})$ & Difference(\%) & F value & p value \\
\hline TA & 26 & $3.25 \pm 0.79$ & $5.66 \pm 1.38$ & $82.41 \pm 57.09$ & 74.07 & $.000^{* * * *}$ \\
\hline 10 & 26 & $8.85 \pm 1.89$ & $11.05 \pm 2.55$ & $26.55 \pm 25.08$ & 35.309 & $.000^{* * * *}$ \\
\hline EO & 26 & $6.70 \pm 1.31$ & $6.21 \pm 1.72$ & $-7.76 \pm 16.87$ & 7.588 & $.011^{*}$ \\
\hline
\end{tabular}

에서는 두 집단의 상호작용이 나타났는데 $(\mathrm{p}=.014)$, 이 결 과로 휴식 상태에서의 대조군과 실험군의 $\mathrm{TA}$ 두께 차이 보다 $\mathrm{AHE}$ 시 대조군과 실험군의 $\mathrm{TA}$ 두께 차이가 더 큰 것 을 확인할 수 있었다. 또한 사후분석 결과 대조군과 실험 군 모두 휴식 상태보다 $\mathrm{AHE}$ 시 $\mathrm{TA}$ 두께가 유의하게 증가 하는 것으로 나타났다. 따라서 압력 바이오피드백 기구 를 사용하여 $\mathrm{AHE}$ 를 수행한 것이 $\mathrm{TA}$ 의 두께증가에 더 도 움이 되었다고 사료된다. 결과적으로 압력 바이오피드백 기구의 도움을 받아 AHE를 수행하였을 때 IO는 두께의
변화가 없었고, $\mathrm{EO}$ 의 두께는 휴식상태보다 $\mathrm{AHE}$ 시 더 증 가했지만 상호작용이 없었기 때문에 휴식상태와 AHE 시 대조군과 실험군의 $\mathrm{EO}$ 근 두께 차이는 일정하게 증가했 다고 할 수 있다. 그러나 $\mathrm{TA}$ 의 두께 변화에는 상호작용이 나타났으며 이것은 휴식상태보다 AHE 시 근 두께가 모 두 증가했지만 실험군의 근 두께 차이가 더 크다는 것이 므로 선택적으로 $\mathrm{TA}$ 두께를 증가시키는 데 도움이 되었 다고 판단된다.

$\mathrm{AHE}$ 를 수행하는 대상자에게 피드백을 주는 방법으 


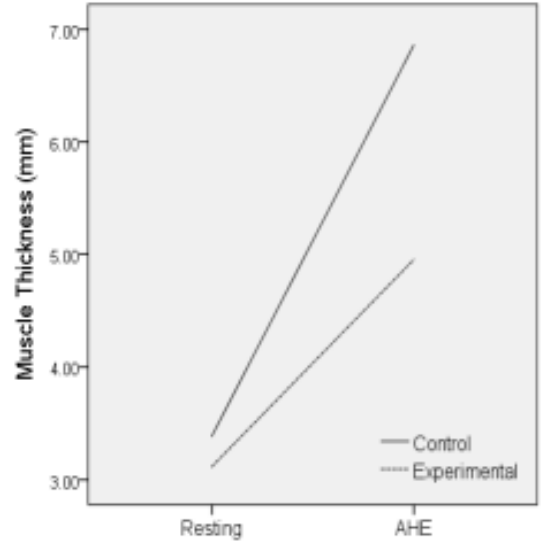

Figure 5. TA Interaction

로는 크게 언어적인 피드백과 촉각적인 피드백만을 주 는 전통적인 피드백 방법, 그리고 이것과 더불어 초음파 를 사용하여 시각적인 피드백까지 제공하는 바이오피드 백(biofeedback) 방법 두 가지로 나눌 수 있다(Teyhen et al., 2005). 일반적으로 바이오피드백 방법이 전통적인 피드 백 방법을 사용하였을 때와 비교하여 지도자가 AHE를 가르칠 때 대상자가 더 빠르게 학습하고 더 정확한 $\mathrm{AHE}$ 를 수행한다(Henry \& Westervelt, 2005). Kwon, et al.(2011) 은 전통적인 피드백을 사용한 그룹은 $\mathrm{EO}$ 와 $\mathrm{TA}$ 의 두께가 모두 증가한 반면, 바이오피드백을 사용한 그룹에서는 $\mathrm{EO}$ 의 두께가 감소하였고 $\mathrm{TA}$ 의 두께가 증가하여 선택적 으로 복부 심부 근육의 수축이 가능했다고 보고하였다. $\operatorname{Hong}(2016)$ 또한 전통적인 피드백을 사용한 그룹에서는 $\mathrm{EO}, \mathrm{IO}, \mathrm{TA}$ 의 두께가 모두 증가하였지만 바이오피드백을 사용한 그룹에서는 $\mathrm{TA}$ 의 두께만 증가했다고 보고하였 다. 하지만 본 연구에서 자가촉진 피드백을 적용한 그룹 에서 $\mathrm{TA}$ 와 $\mathrm{IO}$ 가 유의하게 증가하였다.

그러나 AHE를 수행할 때마다 다른 검사자나 초음파 장비, 또는 압력 바이오피드 백 기구를 이용하여 피드 백을 받는 것이 어렵기 때문에 스스로 촉진하여 해당 근육의 수축 정도를 평가하는 것은 매우 중요하다. 그러나 본 연 구에서는 $\mathrm{IO}$ 와 $\mathrm{TA}$ 가 모두 두께가 증가하여 대상자들이 자가촉진한 결과가 $\mathrm{IO}$ 와 $\mathrm{TA}$ 의 두께증가를 모두 느낀 것 인지 $\mathrm{TA}$ 만의 두께증가를 느낀 것인지 정확히 확인할 수 없었다. 통계적으로는 실험군과 대조군의 비교에서 IO와
$\mathrm{EO}$ 의 두께가 유의미하게 두꺼워지지 않았지만, 실험군 의 $\mathrm{IO}$ 가 $2.84 \pm 0.81 \mathrm{~mm}$ 증가하여 대상자가 느낀 근육의 수 축은 $\mathrm{TA}$ 만이라고 단정할 수 없다고 판단된다. 또한, $\mathrm{TA}$ 수 축 정도가 두 그룹 모두 유의하게 증가하였으나 실험군은 대조군보다 TA가 유의하게 작았다. 하지만 두 그룹에서 모두 $\mathrm{TA}$ 수축이 유의하게 나타나 자가촉진에 의한 $\mathrm{TA}$ 수 축 피드백의 효과가 있다고 판단된다. 따라서 본 연구의 결과에 의하면 자가촉진에 의한 $\mathrm{AHE}$ 의 피드백이 $\mathrm{TA}$ 수 축에 도움이 되었으나 압력 바이오피드백에 의한 피드백 이 조금 더 효과가 있었다고 할 수 있다. 하지만 자가수축 만으로 $\mathrm{AHE}$ 의 $\mathrm{TA}$ 수축 피드백을 줄 수 있다고 판단된다.

$\mathrm{AHE}$ 는 크게 세 가지 지도방식을 사용할 수 있다. 첫 번 째는 「Posterior pelvic tilt $「$ 방법으로써 대상자의 치골결합 (pubic symphysis)을 가슴 쪽으로 당기는 동안 골반을 뒤쪽 으로 회전시켜 요추가 바닥과 평평해지며 복부의 압력이 증가하고 있다는 것을 느끼게 하는 방법이다(Richardson et al., 1992). 두 번째는 Abdominal bracing 방법으로 다른 사람이 복부를 가격하기 전 복부가 긴장하여 힘이 들어 가 단단해지는 것처럼 대상자의 장골능(iliac crests) 바로 위의 허리 부분을 비스듬한 방향으로 힘을 주게 하는 방 법이다(Jang, 2016; Richardson et al., 1992). 세 번째는 Lower abdominal hollowing combined with lumbar spine flattening 방법으로 배꼽을 등 쪽으로 당기는 것처럼 복부를 갈비뼈 아래쪽으로 수축시키는 방법이다(Lee \& Park, 2011; Richardson et al., 1992). 본 연구에서는 위 세 가지 방법 중 마지 막 지도방식을 사용하였다. 이전 연구들에서 위 세 가지 방법을 사용하여 몸통 안정화 운동을 실시하고 그 효과 에 대해 논의하였지만, 대부분 대상자가 스스로 촉진하 여 피드백을 받고 지도하는 방식이 아닌 다른 검사자 또 는 초음파를 이용하여 피드 백 및 지도하는 방식을 사용하 였다. 그 때문에 추후 연구에서는 세 가지 지도방법 중 본 연구에서 사용하지 않은 다른 두 가지 방법도 자가촉진을 사용하여 연구하고, 그 결과가 동일하게 측정되는지 비교 할 필요가 있다.

\section{결론}

바이오피드백 사용 유무에 따른 자가촉진 AHE를 실시 하였을 때, $\mathrm{TA}$ 와 $\mathrm{IO}$ 의 두께는 통계적으로 유의하게 증가 하였고 $\mathrm{EO}$ 의 두께는 감소하여 복부 심부 근육을 수축하 는 데 도움이 되는 것을 확인할 수 있었다. 또한, 압력 바이 
오피드백 기구를 사용하는 것이 $\mathrm{TA}$ 의 두께를 선택적으로 두꺼워지게 하는 것으로 나타났다. 그러므로 자가촉진으 로 $\mathrm{AHE}$ 를 훈련하는 것은 대상자가 다른 검사자의 유무와 상관없이 스스로 $\mathrm{TA}$ 를 수축할 수 있는 방법이다. 또한, 압 력 바이오피드백 기구를 사용하는 것이 다른 근육에 영향 을 미치지 않고 $\mathrm{TA}$ 만을 수축하는 $\mathrm{AHE}$ 훈련에 도움이 될 수 있다고 판단된다.

따라서 $\mathrm{AHE}$ 를 수행할 때마다 검사자나 초음파 장비를 이용하여 피드백을 받는 것이 어렵기 때문에 자가촉진을 이용한 $\mathrm{AHE}$ 훈련을 하는 것은 매우 중요하며, 추후 자가 촉진시 Hook-lying이 아닌 다른 자세와 서로 다른 피드백 방법, 지도방법을 사용한 $\mathrm{AHE}$ 연구와 요통 환자에 대한 효과비교 연구가 필요할 것으로 생각된다.

\section{Acknowlegdement}

이 논문은 2013년 정부(교육부)의 재원으로 한국연구 재단의 지원을 받아 연구되었음 [NRF-2013S1A5A2A0304 5819].

\section{Conflicts of Interest}

The authors declare no conflict of interest.

\section{References}

Critchley, D. (2002). Instructing pelvic floor contraction facilitates transversus abdominis thickness increase during low-abdominal hollowing. Physiotherapy Research International, 7(2), 65-75.

Goldby, L. J., Moore, A. P., Doust, J., \& Trew, M. E. (2006). A randomized controlled trial investigating the efficiency of musculoskeletal physiotherapy on chronic low back disorder. Spine, 31(10), 1083-1093.

Ha, Y., Lee, G. C., Bae, W. S., \& Cho, Y. J. (2013). The Effect of abdominal muscle drawing-in exercise during bridge exercise on abdominal muscle thickness, using for real-time ultrasound imaging. Journal of the Korean Society of Physical Medicine, 8(2), 231-238.

Henry, S. M., \& Westervelt, K. C. (2005). The use of real-time ultrasound feedback in teaching abdominal hollowing exercises to healthy subjects. Journal of Orthopaedic \& Sports Physical Therapy, 35(6), 338-345.

Hides, J. A., Miokovic, T., Belavý, D. L., Stanton, W. R., \& Richardson, C. A. (2007). Ultrasound imaging assessment of abdominal muscle function during drawing-in of the abdominal wall, an intrarater reliability study. Journal of Orthopaedic \& Sports Physical Therapy, 37(8), 480-486.

Hides, J. A., Richardson, C. A., \& Jull, G. A. (1996). Multifidus muscle recovery is not automatic after resolution of acute, first-episode low back pain. Spine, 21(23), 27632769.

Hides, J., Richardson, C., Jull, G., \& Davies, S. (1995). Ultrasound imaging in rehabilitation. Australian Journal of Physiotherapy, 41(3), 187-193.

Hodges, P. W., Pengel, L. H. M., Herbert, R. D., \& Gandevia, S. C. (2003). Measurement of muscle contraction with ultrasound imaging. Muscle \& Nerve, 27(6), 682-692.

Hong, S. K. (2016). Effect of abdominal hollowing exercise with visual feedback on enhancing the transversus abdominis in healty subjects, (Master's thesis). Kyungpook national university, Deagu, Republic of Korea.

Jang, H. R. (2016). The Effect of abdominal bracing and abdominal hollowing technique on the respiratory function of adults in their 20s, (Master's thesis). Daegu university, Gyeongbuk, Republic of Korea.

Jung, D. E., Kim, K., \& Lee, S. K. (2014). Comparison of muscle activities using a pressure biofeedback unit during abdominal muscle training performed by normal adults in the standing and supine positions. Journal of Physical Therapy Science, 26(2), 191-193.

Kisner C, Colby LA (2012). Therapeutic exercise: Foundations and techniques. USA: FA Davis Company.

Kwon, N. H., Lee, H. O., \& Park, D. J. (2011). The use of real-time ultrasound imaging for feedback during abdominal hollowing. Journal of the Korean Society of Physical Medicine, 6(3), 303-310.

Lee, H. O., \& Park, D. J. (2011). Understanding and clinical application of abdominal hollowing exercise: A literature review. Journal of the Korean Proprioceptive Neuromuscular Facilitation Association, 9(2), 9-19. 
Lee, J. C., Lee, S. K., \& Kim, K. (2013). Comparison of abdominal muscle activity in relation to knee angles during abdominal drawing-in exercises using pressure biofeedback. Journal of Physical Therapy Science, 25(10), 1255-1257.

Long, D. M., BenDebba, M., Torgerson, W. S., Boyd, R. J., Dawson, E. G., Hardy, R. W., ... \& Watts, C. (1996). Persistent back pain and sciatica in the United States: patient characteristics. Journal of Spinal Disorders, 9(1), 40-58.

Maher, C., Latimer, J., \& Refshauge, K. (1999). Prescription of activity for low back pain: What works?. Australian Jurnal of Physiotherapy, 45(2), 121-132.

O'sullivan, P. B., Phyty, G. D. M., Twomey, L. T., \& Allison, G. T. (1997). Evaluation of specific stabilizing exercise in the treatment of chronic low back pain with radiologic diagnosis of spondylolysis or spondylolisthesis. Spine, 22(24), 2959-2967.

O'Sullivan, P. B., Twomey, L., \& Allison, G. T. (1998). Altered abdominal muscle recruitment in patients with chronic back pain following a specific exercise intervention. Journal of Orthopaedic \& Sports Physical Therapy, 27(2), 114-124.

O'Sullivan, P., Twomey, L., Allison, G., Sinclair, J., Miller, K., \& Knox, J. (1997). Altered patterns of abdominal muscle activation in patients with chronic low back pain. Australian Journal of Physiotherapy, 43(2), 91-98.

Park, D. J. (2010). The effect of real-time ultrasound imaging feedback during abdominal hollowing in four point kneeling to healthy men. The journal Korean Society of Physical Therapy, 22(22), 1-6.

Park, D. J., \& Lee, S. K. (2013). What is a suitable pressure for the abdominal drawing-in maneuver in the supine position using a pressure biofeedback unit?. Journal of Physical Therapy Science, 25(5), 527-530.

Richardson, C., Jull, G., Hodges, P., \& Hides, J. (1999). Therapeutic exercise for spinal segmental stabilization in low back pain. London: Churchill Livingstone, pp. 211-222.

Richardson, C., Jull, G., Toppenberg, R., \& Comerford, M. (1992). Techniques for active lumbar stabilisation for spinal protection: a pilot study. Australian Journal of Physiotherapy, 38(2), 105-112.

Richardson, C. A., Snijders, C. J., Hides, J. A., Damen, L., Pas, M. S., \& Storm, J. (2002). The relation between the transversus abdominis muscles, sacroiliac joint mechanics, and low back pain. Spine, 27(4), 399-405.

Teyhen, D. S., Miltenberger, C. E., Deiters, H. M., Del Toro, Y. M., Pulliam, J. N., Childs, J. D., ... \& Flynn, T. W. (2005). The use of ultrasound imaging of the abdominal drawing-in maneuver in subjects with low back pain. Journal of Orthopaedic \& Sports Physical Therapy, 35(6), 346-355.

Yun, K. H., \& Kim, K. (2013). Effect of craniocervical flexion exercise using sling on thickness of sternocleidomastoid muscle and deep cervical flexor muscle. Journal of the Korean Society of Physical Medicine, 8(2), 253-261. 